\title{
Study on the Impact of Big Data on Enterprise Accounting Data and Countermeasures
}

\author{
Qin Liu \\ School of Economics and Management \\ Southwest Petroleum University \\ Chengdu, China 610500
}

\author{
Yongju $\mathrm{Gu}$ \\ School of Economics and Management \\ Southwest Petroleum University \\ Chengdu, China 610500
}

\author{
Zhonglin Tang \\ School of Economics and Management \\ Southwest Petroleum University \\ Chengdu, China 610500
}

\begin{abstract}
With the rapid development of Internet technology, the global storage of data and information has achieved an explosive growth, and big data has penetrated the life and work of the people. As an important basis for effective decisionmaking, enterprise accounting data has gradually become one of the most important strategic resources to win the competition. This article aims to analyze the impact of big data on the accounting data collection and process method, data storage, data process and utilization, data output and work methods. In the face of new characteristics of big data, the author proposes measures for data collection and storage, processing and cloud calculation, analysis methods and data output.
\end{abstract}

Keywords - big data; accounting data; countermeasures

\section{INTRODUCTION}

With the popularity and application of cloud computing and Internet of things, the society has entered a time of big data which has been influencing the way of information resource utilization, changing the operation and development patterns of enterprises, affecting traditional accounting model and promoting the reform of accounting information at an unprecedented speed. To achieve the construction of enterprise accounting information will greatly promote the upgrade of enterprise accounting services so serve the economy and society.

As an enterprise management operation, the accounting focuses on the accounting data management. And the accounting data management on the basis of information and network is a general trend, the arrival of big data will affect all aspects of the enterprise accounting data. The use of big data technology to promote the network-based accounting process and accounting data sharing will help to improve the financial management benefits. Relying on the data analysis and mining technology, the accounting data will be transformed into resources for modern enterprises in decision-making, and the roles of accounting data in instructing and supporting the

Funds Project: Sichuan Educational Department, 2015 Scientific Research Project (15SA0010);

Soft Science Research Project in Sichuan Province (No. 2015ZR0203); Southwest Petroleum University, Humanities and Social Science Special Funds) (2015RW002). development of enterprises has become prominent increasingly.

\section{Big DATA AND ACCOUNTING DATA}

\section{A. Big Data}

The big data time is a great time where electronic data achieve an explosive growth, and it has penetrated all aspects of the enterprise operation and management.

The bid data is changing social life and work ways of the people, besides, it also brings a profound impact to the economic and social development as well as modern enterprise management. Facing the big data, traditional accounting data are far to meet the needs of modern enterprises to use accounting data. In the face of a great number of accounting data, traditional financial accounting management tools are unable to collect, process and analyze the real-time data or further transform them into useful information for decisionmakers. Big data has $4 \mathrm{~V}$ attributes, namely, mass volume, diverse variety, high-speed data process and high value and low density.

\section{B. Accounting Data}

An accounting refers an action where the accounting data arising out of the enterprise operation and management are confirmed, calculated, recorded, analyzed and reported to achieve the management and supervision over the enterprise operation. The accounting data have been changed from traditional accounting record tools to the enterprise operation and management resources for decision-making, its source has changed from previous structured to unstructured, with the development of Internet technologies, unstructured data in the enterprise will gradually penetrate into the enterprise operation and management. The value of accounting data is no longer a simple summary or collection as usual, but changes a large number of original data into decision-making resources needed by enterprises through machine learning and statistical methods. 


\section{INFLUENCE OF BIG DATA ON ACCOUNTING DATA}

\section{A. Influence on Accounting Data Collection and Process}

Accounting data are generated in the course of economic activities, and the distinctive features are extensive data sources, a large scale and complex structure. With the rapid development of Internet technologies, diverse electronic equipment and applications of different enterprise information systems make it easy to collect accounting dada from more and more channels. Traditional spatial data collection channels and platforms are relatively single, which are generally structured data. However, with the development of new technologies such as Internet technologies and cloud computing technologies, unstructured data generated by documents, audio and video and images on the basis of social networks and shopping platforms have obtained an explosive growth, users' comments to enterprises, products and services are also important parts of unstructured data that enterprises need to collect. The sources of accounting data are no longer limited to traditional simple structured data, and it has gradually developed into the coexistence of structured data, semistructured data and structured data.

Traditionally, the static structured accounting data sourced from relational database, which is generally managed through enterprise accounting system or financial module of ERP system, such accounting data is usually stored in a structured way. Static unstructured accounting data are mainly collected from the online social platforms, e-commerce shopping platforms and so on, there are various equipment for the data generation. With the development of Internet technologies, such accounting data will continuously penetrate into all aspects of modern enterprise operation and management, and the emergence of cloud accounting promote more and more enterprise accounting software developers to regard the new unstructured data. In addition, the dynamic real-time accounting data related to the location, scenarios and payment data of users' mobile devices will be transmitted to the enterprise cloud accounting platform through the financial software interfaces. The real-time accounting data from different sources with different structures make the enterprise accounting data structure be more three-dimensional.

\section{B. Influence on Accounting Data Storage and Data Mining}

Traditionally the accounting data process architecture is mainly standalone, client/server and browser / server architecture. Under the background of big data, due to the huge scale and complex structure of enterprise accounting data, in order to make full use of the data, it needs to establish a data storage platform. Yet facing the explosive growth of data flow, traditional accounting treatment framework will be unable to meet the calculation of enterprise accounting data. The data take on an exponential change, besides, it has higher requirements on the time validity for the data process, and valid information shall be acquired in real time so as to get results of the analysis quickly and to further make correct decision and rezones as per the trend information in the results.

Typical big data storage and analysis platforms need to complete related data integration, process, analysis and extraction, and allow data mining in real time for application.
Going with the continuous development of Internet technologies, more and more enterprises will start the "big data" process of their own, which will promote the accounting data process from "centralized" to "distributed". More enterprises will adopt modern data process methods, and new data processing structure will emerge one after another.

\section{Influence on Accounting Data Process, Analysis and Use}

After establishment of the big data storage platforms, the analysis of accounting data will be an important part fir information acquisition. With the development of computer technologies, huge amounts of data will be further processed and analyzed for valuable data, refined for use. Traditional computerized accounting is operated by users, from accounting vouchers, books to final financial statements, all of which are in the lack of accounting data analysis, and can not provide effective information for decision-making of enterprises. Traditional results-oriented and long term accounting data process has been no longer applicable for the current data process and use analysis under the background of big data. The accounting data analysis is no longer limited to the traditional relational database mode, under the big data environment, more attentions shall be paid to unstructured and dynamic realtime accounting data, traditional relational database has been unable to meet the needs of accounting data analysis which will be transferred from the data warehouse gradually to the deep learning.

During the big data analysis and process, more and more enterprises adopt various analysis tools such as regression analysis, time series analysis, decision-tree analysis and so on. With the development of data processing technologies, the algorithm used for mining analysis becomes much more complex, and the amount of data used is also very large. The establishment and sharing of enterprise accounting data do good to the sharing of information within enterprises, breaking the "information island" effect between different business systems of different departments. Closed data management models are unable meet the needs of enterprise information management under big data, but the information integration platform built in the enterprises can achieve the real-time transfer of direct data among departments as production, warehousing and procurement. The sharing of accounting data under the big data will help the enterprises to respond quickly in purchase, production and sales.

\section{Influence on Accounting Data Output and Work Methods}

Traditional enterprise data output mainly focuses on the reflection of accounting information, such as routine financial statements and structural analysis diagram. Under the background of big data, data visualization will be a new direction of accounting data application. With the development of new technologies and the increased requirements of data mining, the traditional information output will be unable to meet requirements of information users. The large amounts of complex accounting data are converted into intuitive graphics, charts, even audio and video, based on which, the information are provided to users, making it be a tool of accounting data output and information transmission, clear and readable, easy to access, so that the enterprise decision-makers will regard 
changes in accounting data and make rapid judgment. Therefore, in the time of big data, the information users will pay more attentions to the accounting information simple and easy to understand, which will promote the enterprise accounting data output to change from the "charting" to "visualized".

Enterprise accounting data platforms may provide enterprises with important management resources so as to obtain overall data. Relying on the data resources, before decision-making, prediction and budget management, the enterprises need to conduct overall and relevant analysis on the basis of big data and make the ultimate decisions through collecting data online and offline, historical resources, recent business data and financial data. Through the big data platform, enterprises may access to internal and external data, industrial data and analyze strengths, weakness, opportunities and threats, and continuously monitor and adjust the implementation of enterprise strategies on the basis of data analysis. In addition, the big data platform can be used for data mining to deep understand customers' preferences and habits, so as to establish production strategies satisfying consumers.

\section{COUNTERMEASURES AGAINST INFLUENCES ON ACCOUNTING DATA}

\section{A. Establish Information-based Accounting Data Management}

In order to comprehensively and effectively collect, analyze and process enterprise accounting data, especially the enterprise financial personnel should deeply understand the importance of enterprise accounting data, during the daily operation, try best to ensure the data shall be in a wide source, real and reliable. Only the information-based accounting is established in the enterprises, can it be possible to achieve the data collection, processing and analysis through the information-based platforms and means and further draft the most feasible and effective decision-making programs.

\section{B. Create A Data Sharing Mechanism in An Enterprise}

Under the background of big data, the enterprise data are characterized of wide sources, large scale and relatively decentralized. The enterprise should establish a data sharing mechanism of its own and guarantee the data flow in the enterprise, eliminating the "data island" between departments inside. Create a unified enterprise data exchange standard, allow free data exchange between departments so as to enhance the coordination between departments in the enterprise.

\section{Select New Data Analysis Methods}

With the rapid development of information processing technologies, enterprises are recommended to choose mature big data applications software, in order to save costs, it will be applicable to consider the open source big data management platform and operating system. Advanced technical means and analytical methods can be used to mine, process and analyze the retained accounting data, and find the correlation implied between the data from the vast amount of accounting data, analyze rules between things and predict the future. In addition, the introduction of accounting data online sharing, use of machine learning and statistical computing methods will convert lots of original data into useful information. The new method not only complements the deficiency of single causal analysis method in traditional accounting, but also provides more effective information basis for enterprise's decisionmaking, so as to improve the scientificity and operability of the decision-making. The machine learning technology the big data time brings will bring more dimensions and depth to the enterprise data mining, and will also greatly improve the breadth and depth of enterprise accounting data analysis.

\section{Adopt Visualized Data Output}

With the development of Internet technologies, more and more business process will be achieved in the cloud terminal, and the accounting data collection, processing, use, input and output can be processed in real time so that information users can access to the information in real time, which raise higher requirements to speeds of accounting information collection, process and transmission so as to monitor the market in real time make responses to the changing environments. At the time of big data, data are one of the most important strategic resources for enterprises to win the competition. Meanwhile, to obtain a large amount of accounting information is also to capture the fleeting opportunities. Therefore, in order to provide accounting information easy to understand and convenient to use, the enterprises should actively adopt the "visualized" data output such as the integrated use of graphics, forms, audio and video, animation, and so on.

\section{CONCLUSION}

Under the background of big data and mass data flow with wide sources, the enterprises need more reforms in the establishment, management and application of accounting data so as to meet the preference and demand at the time of information. Lots of unstructured and semi-structured data have become accounting data, which enrich the contents and sources of accounting data. Under the background of big data, enterprises have more diversified ways for accounting data process, and the data analysis are deeper and thorough, and the output of enterprise accounting data is more visible, and the data-based decision-makings are more scientific so as to ensure the scientificity and operability of the decision-making. Therefore, the enterprise managers and financial management should fully understand the changes of accounting data under the background of big data, catch opportunities, brave to challenge and active to learn new data analysis methods and data mining technologies to achieve the effective application of big data in the enterprise accounting and constantly improve the enterprise management level under the background of big data.

\section{REFERENCES}

[1] Zhao Xuhai, Reforms of Multiple Accounting-Based Financial Reports under the Big Data Time [J]. Finance and Accounting Monthly, 2014,11:17-21. 
[2] Fan Yanping, Cao Wei, Characteristics and Application of Cloud Accounting under Big Data $[\mathrm{J}]$. China Business and Market, 2014,06:76-81.

[3] Peng Chaoran, Risk Factors and Countermeasures of Information-Based Accounting in the Big Data Time.

[4] Yuan Zhenxing, Zhang Qingna, Zhang Xiaolin, Zhang Xiaoxue, Challenges of Big Data to Accounting and Countermeasures [J]. Friends of Accounting, 2014,32:89-92.

[5] Zhao Jing, New Characteristics of Enterprise Accounting Data under the Background of Big Data [J]. Finance and Accounting Monthly, 2014,21:105-108.

[6] Geng Yunjiang, Zhao Xiaoxiao, Challenges to Management Accounting in the Big Data Time [J]. Friends of Accounting, 2014,21:105-108.

[7] Liu Congbin, Construction of Information-Based Accounting under the Background of Big Data and Could Computing J]. Studies of Finance and Accounting in Education, 2015,01:65-67.

[8] Wang Xiaojuan, Wan Yinghong, Building of Quality Evaluation Indices System of Accounting Information in the Big Data Time, Study on Vagueness-based Complex Evaluation Method, [J]. Finance and Accounting Monthly, 2015,14:74-77.

[9] Cheng Ping, Zhang Yadi, Building of Cloud Accounting-based Audit Framework in the Big Data Time [J]. Friends of Accounting, 2015,24:134-136.

[10] Xu Jinye, Xu Lin, Risks for Building Data Analysis-based Enterprises and Control Mechanism Design [J]. Friends of Accounting, 2013,27:117-119. 